\title{
Interviewing When You're Not Face-To-Face: The Use of Email Interviews in a Phenomenological Study
}

\author{
Chandra Bowden and Sebastian Galindo-Gonzalez \\ Department of Agricultural Education and Communication, \\ University of Florida, Gainesville, FL, USA
}

\author{
chbowden@ufl.edu sgalindo@ufl.edu
}

\begin{abstract}
As Internet usage becomes more commonplace, researchers are beginning to explore the use of email interviews. Email interviews have a unique set of tools, advantages, and limitations, and are not meant to be blind reproductions of traditional face-to-face interview techniques. Email interviews should be implemented when: 1) researchers can justify email interviews are useful to a research project; 2) there is evidence that the target population will be open to email interviewing as a form of data collection; and 3) the justification of the email interview supports the researchers' theoretical perspective. The objective of this study was to develop an email interviewing methodology. As with other forms of qualitative interviewing, it is important that the researcher: 1) identifies constraints; 2) adequately prepares for the interview; 3) establishes rapport; 4) asks appropriate questions; 5) actively listens; and 6) ends the email interview appropriately.
\end{abstract}

Keywords: Millennials, email interviewing, Gadamerian Hermeneutical Phenomenology, mixeduse communities

\section{Introduction}

As more people congregate online, qualitative researchers are exploring the use of online tools for research (Abrams, Wang, Song, \& Galindo-Gonzalez, 2014; Jones, 1999; Hine, 2000, 2004, 2005; Mann \& Stewart, 2000; Seymour, 2001; Synnot, Hill, Summers, \& Taylor, 2014). These tools include email interviewing, instant messaging, and (a)synchronous online focus groups. Written communication can indeed induce strong feelings and reactions in its readers (Watson, Peacock, \& Jones, 2006). Williams (2009) attested to becoming upset while reading email interviews of participants' stories of abuse and self-harm. She felt that this emotional reaction helped her to interpret the experiences of participants. Indeed, writing often has a cathartic effect on the

Material published as part of this publication, either on-line or in print, is copyrighted by the Informing Science Institute. Permission to make digital or paper copy of part or all of these works for personal or classroom use is granted without fee provided that the copies are not made or distributed for profit or commercial advantage AND that copies 1) bear this notice in full and 2) give the full citation on the first page. It is permissible to abstract these works so long as credit is given. To copy in all other cases or to republish or to post on a server or to redistribute to lists requires specific permission and payment of a fee. Contact Publisher@InformingScience.org to request redistribution permission. author, helping to work through emotions (Etherington, 2003; Pennebaker, 1993). Using computers to collect qualitative data easily fits into most contemporary technologically imbued lifestyles. In particular, email has become a normal and responsible mode of communication (Burns, 2010). 


\section{The Values and Limitations of Email Interviews}

Email interviews cannot be implemented as a reproduction of traditional face-to-face interview techniques. It is a data collection method with a unique set of tools, values, and limitations (Graffigna \& Bosio, 2006).

\section{Values}

Eliminates the boundaries of time and space. The use of computers allows researchers to extend their access to potential participants. This can be especially advantageous when geographical distance is too great to travel (Burns, 2010; Chen \& Hinton, 1999; Dimond, Fiesler, DiSalvo, Pelc, \& Bruckman, 2012; James \& Busher, 2009; Mann \& Stewart, 2000), and when seeking access to difficult to reach populations such as the sick (Cook, 2012; Synnot et al., 2014), the military (Opdenakker, 2006), the elderly (Brondani, MacEntee, \& O'Connor, 2011), and teen drug users (Barratt, 2012).

Reduces research costs. Email interviews save time and reduce project costs because there is no required travel in order to interview (Fontes \& O'Mahony, 2008; Opdenakker, 2006), neither are there transcription costs (Bowker \& Tuffin, 2004; Fontes \& O'Mahony, 2008; Opdenakker, 2006; Seymour, 2001).

Prioritizes participants' comfortability. Tanis (2007) posits that written forms of communication allow for greater participation by people who may have speech and/or hearing difficulties. Additionally, with email interviews, participants can reply to questions at his/her convenience (Bowker \& Tuffin, 2004; Burns, 2010; Cooper, 2009; Opdenakker, 2006). Being able to respond to interview questions in the comfort of one's home or during 'down time' may encourage participants to feel safer about sharing their personal experiences (Bowker \& Tuffin, 2004; Egan, Chenoweth, \& Mcauliffe, 2006), including experiences that may be particularly sensitive and/or embarrassing (Deakin \& Wakefield, 2014).

Encourages iterative reflection throughout the interview process. In email interviews, both the researcher and the participant have more time to reflect on the question(s) and provide thoughtful answers. Researchers also have time to iteratively interpret data before asking followup questions (Opdenakker, 2006; Ratislavová \& Ratislav, 2014; Sammel, 2003).

Streamlines the interview. Having the interview already transcribed eliminates transcriber bias when translating audio data to textual data (Ayling \& Mewse, 2009). Additionally, there is no background noise being recorded during the interview (Opdenakker, 2006). Data quality is essentially the same between email and face-to-face interviews (see Meho, 2006). However, multiple studies have demonstrated that data collected online via text is more succinct than data that is collected verbally (Abrams et al., 2014; Benford \& Standen, 2011; Campbell et al., 2001; Dimond et al., 2012; Egan et al., 2006; Nicholas et al., 2010; Synnot et al., 2014). Although the transcripts of online interviews are typically shorter than face-to-face interviews, the online groups tend to provide more concrete examples in answering interview questions (Synnot et al., 2014). Face-to-face interviewees are more likely to share more stories, which potentially provide additional data that online participants do not generate, but these additional stories are not always relevant to the research questions (Campbell et al., 2001; Nicholas et al., 2010; Synnot et al., 2014).

\section{Limitations}

Marginalized research method. Face-to-face interviews are often privileged over email interviews as a primary means of data collection as face-to-face interviews have been the norm for many decades. Typically, face-to-face interviews are implemented as an uncontested component 
of the research design, whereas online interviews are viewed as a second choice alternative when face-to-face interviews are not possible (Deakin \& Wakefield, 2014).

May marginalize available participants. With email interviews, participants must have access to the Internet and be competent in computer use (Egan et al., 2006; Jowett, Peel, \& Shaw, 2011).

Lack of social cues. Face-to-face interviews have the advantage of being conducted synchronously in both time and place. That is, the interviewer and interviewee can see each other and take advantage of social cues such as paralanguage, body language, pauses, inflection, and tone (Barratt, 2012; Opdenakker, 2006). The lack of social cues in email interviews, however, may increase ambiguity and misinterpretations of the messages exchanged (Chen \& Hinton, 1999).

Delay in receiving data and other data issues. Because participants in email interviews respond to questions at their convenience, researchers may have to wait several days to receive a response (Cooper, 2009; Opdenakker, 2006). The delay in response may also eliminate spontaneity as a source of data (Opdenakker, 2006). The time lag in response increases the likelihood that participants may forget to reply at all (Fontes \& O'Mahoney, 2008; Kivits, 2005), and increases the opportunities to loose participants at multiple stages throughout the interview (Burns, 2010).

Issues with logistics. Because researchers and participants never interact physically, it can be a challenge to establish rapport prior to the interview (Kivits, 2005). Although there is no background noise that is typically prevalent during face-to-face interviews, the researcher has much less control over other distractions the participant may face while interviewing, and may not even be aware of distractions participants face such as multi-tasking (Chen \& Hinton, 1999; Voida, Mynatt, Erickson, \& Kellogg, 2004). Additional logistical issues include not being able to verify if the participant is whom they say they are (Fontes \& O'Mahoney, 2008; James \& Busher, 2009); difficulty analyzing transcripts due to no audio recordings to refer to, and limited or absent paralinguistic cues (Synnot et al., 2014); and difficulty ending the interview session as email interviews may take place over an extended period of time (Kivits, 2005; Opdenakker, 2006).

As with any methodology, there are limitations that need to be mitigated to ensure reliable and valid results. Table 1 presents common limitations researchers encounter when conducting email interviews and provides strategies to overcome them.

Table 1. Limitations of email interviews and strategies to overcome them

\begin{tabular}{|l|l|}
\hline \multicolumn{1}{|c|}{ Limitation } & \multicolumn{1}{c|}{ Suggested Strategy to Overcome } \\
\hline $\begin{array}{l}\text { Research participants must have } \\
\text { access to the Internet and have } \\
\text { sufficient computer literacy skills }\end{array}$ & $\begin{array}{l}\text { Digital divide is increasingly shrinking as technologies } \\
\text { become less expensive and more ubiquitous. Offer alter- } \\
\text { natives to email interviewing. }\end{array}$ \\
\hline $\begin{array}{l}\text { Lack of social cues to demonstrate } \\
\text { listening and understanding }\end{array}$ & $\begin{array}{l}\text { Actively engage in dialogue, not silence, to demonstrate } \\
\text { listening and understanding (Mann \& Stewart, 2002). }\end{array}$ \\
\hline $\begin{array}{l}\text { Researcher may need to wait sev- } \\
\text { eral days to receive response from } \\
\text { participant }\end{array}$ & $\begin{array}{l}\text { Inform participants of the time frame for the actual in- } \\
\text { terview. Send email reminders about answering inter- } \\
\text { view questions (Meho, 2006). }\end{array}$ \\
\hline Building rapport may be stifled & $\begin{array}{l}\text { Be deliberate in establishing rapport before asking inter- } \\
\text { view questions (Illingworth, 2001; Kivits, 2005; Mann } \\
\text { \& Stewart, 2002). }\end{array}$ \\
\hline $\begin{array}{l}\text { Uncertainty as to whether partici- } \\
\text { pant is who they say they are }\end{array}$ & $\begin{array}{l}\text { Evaluate how the story is constructed and consistency of } \\
\text { story to ensure trustworthiness (James \& Busher, 2009). }\end{array}$ \\
\hline $\begin{array}{l}\text { More points of "loss" from partic- } \\
\text { ipant drop off/lack of interest }\end{array}$ & $\begin{array}{l}\text { Inform participants that research is bounded by specific } \\
\text { length of time and/or number of sessions (Meho, 2006). }\end{array}$ \\
\hline
\end{tabular}


Interviewing in a Phenomenological Study

A major theme embedded within these suggested strategies is to actively engage the research participant in communication at the initiation of the research relationship and throughout the entire interview process.

\section{Research Context}

This study was the pilot component of a larger project. In this part, we wanted to answer the question, "How do Millennials make sense of their experiences living in mixed-use communities?", and used this study as a guide to develop a method for how to conduct interviews via email. The first author of this paper played an active role in the study as interviewer, while the second author was a peer researcher who supported the first author in her interviews.

\section{Why Millennials?}

Millennials are the largest American generational cohort since the Baby Boomers. Representing $25 \%$ of the American population, there are currently 80 million Millennials (Duggal, 2013) born between 1977 and 2000 (Pew Research Center, 2010). Millennials are the most ethnically diverse generation in American history with $40 \%$ of them being either Latino or African-American (Belden Sussonello Strategists, 2013). Millennials spend over 200 billion dollars annually (Barkely Independent Advertising, 2012). With older Millennials (ages 18-34) beginning to enter the housing market, it is important to determine what factors influence their housing consumer choices as their sheer numbers and economic footprint could change the face of the American housing market.

There is evidence that suggests Millennials want multiple uses from their homes and neighborhoods. Duggel (2013) conducted a survey and determined that community gathering spaces, flexible floor plans and homes equipped with infrastructure to support their personal technologies were most important to Millennials. Millennials also want their neighborhoods to be green, walkable, located near transit, restaurants, and/or libraries, and contain a mix of housing styles and types.

\section{Our Participants}

We had a total of five participants (Table 2) selected via convenience and snowball sampling.

Table 2. Demographic information about participants

\begin{tabular}{|c|c|c|c|c|}
\hline Participant & Age & Location & Tenure & Dominant Lifestyle \\
\hline Lynn & 25 & Gainesville, FL (City Limits) & Homeowner & Spaces \\
\hline Laura & 33 & Gainesville, FL (Downtown) & Renter & Well-Being \\
\hline Dionna & 32 & Philadelphia, PA (City Limits) & Renter & Spaces \\
\hline Elias & 26 & New York, NY (City Limits) & Renter & Well-Being \\
\hline Manny & 34 & Fort Worth, TX (Downtown) & Renter & Well-Being \\
\hline
\end{tabular}

First, we contacted local Millennials we knew who lived within our city limits. From there, we asked our participants to provide the names of additional Millennials who would qualify for participation in our study. We also asked younger faculty members for the names of additional Millennials who may be able to participate. Each of the participants we contacted agreed to participate in the study. Demographic characteristics of the participants include: age, location (where 
downtown is the city center), tenure (renter or owner), and dominant lifestyle. Lifestyle was determined via a questionnaire (see Appendix) where participants rated how important a particular neighborhood and community factor was to them in choosing their current residence. Each email interview was limited to a maximum number of 10 email exchanges or 14 days, whichever came first. Of the participants, 'Elias' had the fewest number of email exchanges (eight). All other participants had 10 exchanges (including reminder emails), and lasted 14 days.

\section{Conducting Email Interviews}

In the same vein as Jones and Alony (2011), we will integrate the theoretical guidelines with how we used email interviews to collect data. This section will include first and third person forms of communication, where first person indicates the practical insights we gleaned from implementing this process (which is also in italics for clarity) and third person indicates the theoretical underpinnings of this method. Each section will be introduced with a question.

\section{Does my research lend itself to email interviews?}

Online interviewing is not an "easy option" (James \& Busher, 2009, p. 40) for data collection, and should be implemented only when researchers can justify that this form is useful for their research project (Cooper, 2009). Researchers who conduct email interviews must have a strong commitment to the topic of interest, the participants, and the interview process itself (Kivits, 2005).

Because email interviews remove the element of spontaneity as a part of data collection, a researcher needs to determine if spontaneity in response to the interview questions (Williams, Clausen, Robertson, Peacock, \& McPherson, 2012) and direct probing (Meho, 2006) are essential components in answering the research questions.

We wanted to conduct an exploratory study to understand how Millennials make sense of their lived experiences in mixed-use communities. Although we live in a college town and have several mixed-use neighborhoods, we felt that the local demographic available to us was too homogenous to gather a diversity of perspectives. So, we decided to expand our research pool to Millennials throughout the United States.

\section{What evidence is there that suggests my target population would be open to online data collection?}

Before committing to email interviews it is imperative that researchers first determine whether or not their participants would be responsive to this form of data collection. Boshoff, Alant, \& May (2005) assert that asynchronous online research can help facilitate research of individuals that lead busy professional lives.

We know that Millennials value flexibility in obligatory tasks and are likely to rely on technology to help them multi-task since they do not like wasting time (Sweeney, 2006). We also know that generally Millennials feel comfortable communicating online. Turkle (2011) conducted an ethnographic study of communication among adolescents who reported that texting was the only way they felt they could connect to their emotions. Turkle (2011) concluded that as thumbs-based communication continues to increase, (e.g., texting, instant messaging, online forums, social sites, etc.), so will individuals' preferences for text-based communication. 


\section{Does this data collection method support my research theoretical perspective?}

One's theoretical perspective is a philosophical stance that informs their research methodology and method. We positioned ourselves within the theoretical perspective of Interpretivism, specifically, Gadamerian Hermeneutical phenomenology. For Gadamer (1989), hermeneutical understanding seeks to utilize the horizon of one's past experiences to interpret the horizon of present experiences. Understanding takes place when the past and present horizons of the researcher fuses with the past and present horizons of the participant, and a new horizon of understanding is created.

We decided to conduct a Gadamerian Hermeneutical phenomenology as we wanted to coconstruct knowledge with our participants. The hermeneutical aspect meant that we would utilize an iterative data analysis approach such that with each successive email, we reached the essence of the participants' experiences within mixed-use communities. We sought to compare the parts and whole of each participant's experiences. The time delay built into email interviews incorporated a reflexive component to data collection and supported a more iterative data analysis. The Gadamerian aspect of this phenomenology meant that knowledge would be co-constructed with our participants where, at the conclusion of the interview, the horizon of experience of both the participants and the researcher expanded with new understanding.

Gadamer (1989) asserts that his phenomenology encourages both the researcher and participant to expand their horizons of understanding through communication, which requires that both parties be open and flexible to the changing dynamics of the interview process.

The Gadamerian aspect of this study was initially uncomfortable for Chandra, the one who conducted the interviews, who by nature is private and values boundaries between the work and the personal. She was aware of her past horizons of experiences including her struggles as a Millennial, and how she makes sense of how her previous professional and personal experiences have shaped who she is as a doctoral student, and her feelings of pride/shame of her development thus far. She was surprised when, at the request of a participant, she was asked to express these life experiences.

Chandra \{at the conclusion of her introductory email\}: If you don't have any objections, it would be nice to learn a little more about you.

Manny: No objections here, I'm pretty open--- \{After a three paragraph introduction $\}$--- I am curious, what's your exigence [sic] in your line of work? Where's your gravitas? Or what are you most passionate about/interested in?

With respect to sharing her present horizon of understanding, Chandra chose to tell a participant her personal reaction to the participant's thoughts about the local food movement. Both Chandra and the participant, 'Laura', were able to expand their understanding of their opinion of the local food movement.

Chandra \{in response to Laura's full endorsement of the local food movement\}: I struggle with 1) having personal beliefs that local, less processed food is healthier, 2) having a desire to see people from all socioeconomic backgrounds be able to have a choice on the types of food they eat, and where they live, and 3) wondering if I am imposing my beliefs on them---What are your thoughts on this? And what perspective can you provide as a member of a local community that values the power of choice in how residents spend their money in order to sustain their community, and believes in the power collective action? 
Laura: You brought up some good points in your last email. I have spoken with XXX and do agree with many of her viewpoints on local food. I should add to my previous statements that there may not be one perfect model for anyone/everyone---

\section{What are my constraints?}

Email interviews remove time constraints from the participant, allowing for more thoughtful and detailed responses (Mann \& Stewart, 2000; Murray, 2004; Tates et al. 2009). That does not, however, preclude time constraints imposed upon the researcher.

We were excited to begin conducting interviews in a novel manner; we quickly realized, however, that there were time constraints on the number of interviews that we could conduct simultaneously. Iterative interviewing is labor intensive as data analysis occurs throughout the interview. We only conducted two interviews at a time as we felt that allowed us to be fully engaged with our participants and provided adequate time to read, analyze, and reply to emails in a timely fashion.

\section{How do I prepare for an email interview?}

Typically, the individuals that researchers may want to interview via email are found online. Recruitment strategies include individual solicitation, snowballing, listservs, message boards, discussion groups, and personal research websites (Meho, 2006).

We created a personal research website that explained the study, and solicited participants via snowball sampling. We laid the groundwork for the relationship that we would establish with participants by communicating our research objectives and establishing the boundaries of privacy issues on our website. Research participants who chose to enroll in the study completed an electronic consent form and were emailed a brief demographic questionnaire in order to determine their dominant lifestyle factor and values. The first interview question was dictated by their primary lifestyle factor, and their dominant value(s) supported our analysis of their responses.

\section{"How-to" conduct email interviews}

Establish rapport. The success of any qualitative interview is contingent on how well the researcher establishes rapport with participants. Much of the literature on qualitative interviewing is dedicated to establishing rapport (Shaw, 2010). Before beginning the interview process, it is important that the researcher gets to know the participant and establish trust (Mann \& Stewart, 2002). One way to establish trust is to demonstrate a shared identity with participants. Indeed, many online researchers suggest that self-disclosure early in the interview process is essential to a fruitful interview experience (Kivits, 2005; Illingworth, 2001; O’Connor \& Madge, 2001).

Before we sent any interview questions, we used our first email exchange to introduce Chandra. She shared information about her age, work, and hobbies and, if participants felt comfortable doing so, asked them to do the same. We were able to pick up a lot about the personalities of the participants based on their responses to that first email. For instance, we perceived that with 'Manny', it would not be as much of an effort to get rich descriptions from him, but with 'Elias', Chandra would have to do more probing to get to share.

Chandra \{at the conclusion of her introductory email\}: If you don't have any objections, it would be nice to learn a little more about you.

Manny: No objections here, I'm pretty open--- \{After a three paragraph introduction $\}$---I am curious, what's your exigence in your line of work? Where's your gravitas? Or what are you most passionate about/interested in?

Elias \{After writing a one paragraph introduction\}: There is a lot more to tell, but introduction has never been my forte. Let me know how best to assist your research. 
Interviewing in a Phenomenological Study

O'Connor and Madge (2001) assert that online interviewing is less formal than face-to-face interviewing, and that their efforts in establishing rapport were perhaps unnecessary.

We disagree. Kivits (2005) asserts that establishing relationships was a prerequisite to gathering sufficient, rich data, and we found this to be true in our study as well.

Asking questions. Embedding questions within the body of the email results in a significantly higher response rate than utilizing questions that are listed as part of an attachment (Dommeyer and Morlaty, 2000). In a typical phenomenological interview, the first question is rather general and asks the participant to explain an experience in detail (Lavarty, 2003).

After participants completed a demographic survey, the first interview question was asked based on the dominant lifestyle factor of each participant. There were four lifestyle factors: spaces, well-being, social, and environtech. Spaces: Tell me about a time when you felt that the spaces within your home and/or neighborhood really suited your particular needs for an occasion. Wellbeing: Tell me about a time when you felt that the layout, vibe, or residents of your home/neighborhood made you feel safe or promoted your overall well-being. Social: Tell me about your favorite memory when you were able to be social with your family or friends while in your home and/or neighborhood. Environtech: Tell me about a time when you were able to live out pro-environmental behaviors in your home and/or neighborhood. No matter the interview question, participants were encouraged to submit a photo (with a signed photo consent form, if applicable) of images within their home and/or neighborhood.

Sammel (2003) conducted a Gadamerian Hermeneutical phenomenology with environmental educators. At the first interview, Sammel used questions to guide the interview. At the follow up interview, she used a list of quotes from the first interview in lieu of new questions to deepen her understanding of how these educators made sense of their experiences. She used questions in the second interview only for clarification.

In our study, each new exchange with our participants included references to previous writings with an interpretation and request for clarification.

Chandra $\{$ to Elias $\}$ : I really appreciate your response. It was very enlightening. It seems that you are 'cool' with your neighborhood, but not 'enjoying' your neighborhood. Is this a fair conclusion? Please let me know. I'd like to ask you a few follow-up questions about what your needs are and how your neighborhood meets (or doesn't meet) your needs---

In order not to overwhelm participants, it is important that the researcher not ask too many questions at one time (Burns, 2010). The researcher must determine the most prevalent themes that they would like to explore in each email exchange.

Listening. This skill is essential in email interviewing and may be challenging to master as there are little to no paralanguage cues to employ to demonstrate listening. While interviewing online, it is important that the researcher realizes that "listening needs to be expressed as words, not silence" (Mann \& Stewart, 2002, p. 618). Letting the participant know you interpret what is shared is critical to minimizing miscommunication.

Chandra: Thanks again for replying to my questions. It seems that the Wissahickon Valley Trail is an important space in your community because it provides a tranquil location for you to maintain your social connections. Did I interpret this correctly? I'd like to ask you a few follow up questions about the Trail and your social ties.

Dionna: Yes, that is a correct interpretation. 
Finally, it is important not only to "hear" what is spoken, but what is also not spoken (Kvale, 1996).

Elias: As for "how your neighborhood meets (or doesn’t meet) your needs," I am really unable to assess that at this time because I am unsure of what needs my neighborhood should meet. [Wow! He does not look for external fun, activities. He sounds lonely.] Not venturing out much does not help my case. [He doesn't seem to be engaged with his community.] At one point, and still, I love very active/loud areas [Something is different, Elias is usually more engaged, feeds off of energy, gives out energy that is more upbeat] but now I am bear/stand neighborhoods with a slower pace.

Ensure privacy. It is important that researchers handle sensitive information with discretion and periodically remind participants that their privacy will be protected (Kivits, 2005).

Chandra: On another note, I was talking with my methodologist this morning. He mentioned that my name dropping (i.e., XXXXX \& XXXXX) may lead my participants (namely you) to believe that I talk about you with others. I want you to know I have not mentioned your responses to anyone, and when sharing my data with my methodologist, I removed identifying information before sharing it with him.

Laura: No worries on the name dropping - I realize our interview may have been a little less formal than your others will be, but thank you for bringing it up and ensuring confidentiality.

Elias: I decided to return to NYC for reasons that I would not like to disclose in this study. XXXX may know the reason, but I do not want to discuss it here. Over drinks, maybe. Just kidding.

Chandra: No worries about not sharing why you left Oregon. When you said over drinks, I laughed (a good laugh). I assume you're taking life's detours in stride and that's all good.

I want you to know that I do not talk with XXXX about my study, or about my participants. I thanked her for sending out my information, and told her two people responded to her call, but did not tell her who they were.

XXXX doesn't know that I know you.

I wouldn't tell your business, anyway. This is why I asked you to provide an alias, so that I would not inadvertently provide any identifying information. And, when I share my interviews with my professor, I always remove your email. Gossip is grimy, and I'm not into that.

End the interview (or responding when the interview seems to end when you haven't finished collecting data). Asynchronous online data collection, such as email interviews, typically last several weeks (Williams et al., 2012), and it can be difficult for both the researcher and participant to accept closure after the email interview has ended (Kivits, 2005). To ensure that the study actually comes to an end, researchers can create an email account specifically dedicated to the research project so that they can delete the contact list and preserve research participants' confidentiality (Fontes \& O’Mahoney, 2008).

At the conclusion of our interviews, we thanked the participants for their participation and informed them that we would share the results of the study with them once we analyzed all interviews. We sent each participant a PowerPoint presentation containing the major themes, subthemes, and contradictory themes shared by participants.

Alternatively, the interview can end at the discretion of the participant. This can be overt (expressing a desire to end the interview) or covert (not replying to follow up emails). 
Interviewing in a Phenomenological Study

In our study, the interview was bounded by 10 email exchanges or 14 days, whichever came first. A relatively short interview period was advantageous for us both in securing participants and limiting the sudden feeling of loss of a relationship between researcher and participant (Kivits, 2005). Even with our short interview window, we had two participants end the process covertly. Though it has been suggested that busy professionals may prefer the email interview method (Boshoff et al., 2005), we are unable to conclude that this method ensured the greatest retention of our participants, and we are unaware of literature that compared the attrition of professionals versus non-professionals interviewed via emails.

Kivits (2005) asserts that the primary challenge in her study was to preserve participant interest in the interview. Because the email interview is carried out over an extended period of time, the original excitement tends to wane and increases the likelihood for participant attrition. One of the first warning signs of attrition is an extended time lag between responses. What can a researcher do to encourage the consistency of the interview when it takes their participants longer than usual to respond to questions?

We experienced delays in participants completing their demographic survey and/or replying to interview questions. Because of our relatively short interview window, we chose to give participants 48 hours (on rare occasions 72 hours) to respond to our inquiries. Most participants replied to our follow-up emails. There were two occasions when participants did not reply to our repeated requests for information. 'Elias' only partially completed his final evaluation survey, and 'Manny' did not reply to our follow-up email requesting feedback on themes that Chandra gleaned from their interview.

A limitation of email interviewing is that there are multiple places where the researcher can 'lose' participants before the interview is complete. Researchers must decide if, or how, to use partial data.

With both of these participants, we chose to use what we had.

\section{How participants felt about email interviews}

To our knowledge, no studies exist which explore how Millennials perceive an email interview research experience.

As part of reflecting on the usefulness of this method with Millennials, we sent participants an open-ended survey at the conclusion of the interview and asked for feedback about the interview process. The participants liked being able to reply to interview questions at their convenience, and having a time limit to the interview (i.e. 10 email exchanges or 14 days) made them more likely to participate, as without this time constraint, they might not have participated. Having a time constraint on the interviews was advantageous to us as well. It encouraged us to begin analyzing new interviews quickly after we received them, which helped to keep the ongoing conversation fresh and relevant.

Obtaining a signed consent form for photos was a deterrent for nearly all participants. Those who did choose to submit pictures did not submit images with identifiable people in them in an effort to avoid having a form signed. Participants appreciated that there were a limited number of questions with each email exchange, and enjoyed receiving the summaries of their responses to our interview questions. This feedback from the respondents is important in iterative data analysis. The participants enjoyed their rapport with Chandra, but did not feel that her self-disclosure was necessary for them to want to share their responses. This is interesting because we intentionally made sure that Chandra shared her historical and present horizons of experience as part of a Gadamerian Hermeneutical phenomenology. 


\section{Conclusion}

The objective of this study was to develop a method on how to conduct email interviews with Millennials. Email interviews appear to be a strong data collection method for this demographic as most Millennials are computer literate and have access to the Internet (Turkle, 2011). Millennials also value flexibility when completing responsibilities and rely on technology to help them multi-task. We feel that for an exploratory study, this data collection was sufficient. A comparative study with another interview method, such as face-to-face, would be necessary to determine if similar themes emerged no matter the interview method. Like all other forms of qualitative interviewing, it is important that the researcher: 1) establishes rapport; 2) asks appropriate questions; 3) actively listen; and 4) end the interview appropriately.

\section{A Personal Reflection on Email Interviewing}

Email interviewing was a satisfactory data collection method for this study. As a pilot, we had no available funds to collect data that would inform a larger dissertation study. This method allowed us to obtain and utilize preliminary data efficiently. This data collection method situated us to think of our target audience from the inception of this project, including the design of our research website, how we established rapport, and how we conducted the interview. Analyzing communicative data without non-verbal cues proved a challenged as we wanted to ensure that we honored the perspectives of our participants. This required close reading of the email messages. The iterative data analysis process, due to the time delay, however, helped to make the analysis run more smoothly as we could ask for feedback on our interpretations and clarify any misunderstandings. Our participants felt pleased to provide their insight and appreciated that we shared communication that resonated with them.

\section{References}

Abrams, K., Wang, Z., \& Galindo-Gonzalez, S. (2014). Data richness tradeoffs between face-to-face, online audio-visual, and online text-only focus groups. Social Science Computer Review, in press.

Ayling, R., \& Mewse, A. (2009). Evaluating email interviews with gay men. Qualitative Health Research, 19(4), 566-576.

Barkley Independent Advertising. (2012). Millennials research. Retrieved April 5, 2014, from https://www.barkleyus.com/millennials

Barratt, M. (2012). The efficacy of interviewing young drug users through online chat. Drug and Alcohol Review, 31, 566-572.

Belden Russonello Strategists. (2013). Americans' views on their communities, housing and transportation. Analysis of a national survey of 1,202 adults. Prepared for the Urban Land Institute. Belden Russonello Strategists: DC.

Benford, P., \& Standen, P. (2011). The use of email-facilitated interviewing with higher functioning autistic people participating in a grounded theory study. International Journal of Social Research Methodology, 14, 353-368.

Boshoff, K., Alant, E., \& May, E. (2005). Occupational therapy managers perceptions of challenges faced in early intervention service delivery in South Australia. Australian Occupational Therapy Journal, 52, 232-242.

Bowker, N., \& Tuffin, K. (2004). Using the online medium for discursive research about people with disabilities. Social Science Computer Review, 22(2), 228-241.

Brondani, M., MacEntee, M., \& O'Connor, D. (2011). Email as a data collection tool when interviewing older adults. International Journal of Qualitative Methods, 10(3), 221-230. 
Interviewing in a Phenomenological Study

Burns, E. (2010). Developing email interview practices in qualitative research. Sociological Research Online, 15(4). Retrieved February 1, 2014, from http://www.socresonline.org.uk/15/4/8.html

Campbell, M., Meier, A., Carr, C., Egna, Z., Reedy, A., \& Zheng, B. (2001). Health behavior changes after colon cancer: A comparison of findings from face-to-face and on-line focus groups. Family Community Health, 24(3), 88-103.

Chen, P., \& Hinton, S. (1999). Real-time interviewing using the world wide web. Sociological Research Online, 4(3). Retrieved January 5, 2014, from http://www.socresonline.org.uk/4/3/chen.html

Cook, C. (2012). Email interviewing: Generating data with a vulnerable population. Journal of Advanced Nursing, 68(6), 1330-1339.

Cooper, R. (2009). Online interviewing: It's not as simple as point and click. The Weekly Qualitative Report, 2(43), 250-253.

Deakin, H., \& Wakefield, K. (2014). SKYPE interviewing: Reflections of two PhD researchers. Qualitative Research, 14(5), 603-616.

Dimond, J., Fiesler, C., DiSalvo, B., Pelc, J., \& Bruckman, A. (2012). Qualitative data collection technologies: A comparison of instant messaging, email, and phone. In Proceedings of the 17th ACM international conference on supporting group work (pp. 277-280). ACM.

Dommeyer, C., \& Moriarty, E. (2000). Comparing two forms of an email survey: Embedded vs. attached. International Journal of Market Research, 42(1), 39-50.

Duggal, M. (2013). The impact of gen Y on housing: The market and demographic perspective. APA Virginia Annual Planning Conference. Leesburg, VA.

Egan, J., Chenoweth, L., \& Mcauliffe, D. (2006). Email-facilitated qualitative interviews with traumatic brain injury survivors: A new and accessible method. Brain Injury, 20(12), 1283-1894.

Etherington, K. (2003). Trauma, the body and transformation. In K. Etherington (Ed.). Trauma, the body and transformation: A narrative inquiry (pp.22-38). UK: Jessica Kingsley Publishers.

Fontes, T., \& O'Mahony, M. (2008). In-depth interviewing by instant messaging. Social Research Update, $53,1-4$.

Gadamer, H. (1989). Truth and method. New York: Seabury Press.

Graffigna, G., \& Bosio, A. (2006). The influence of setting on findings produced in qualitative health research: A comparison between face-to-face and online discussion groups about HIV/AIDS. International Journal of Qualitative Methods, 5(3), 1-16.

Hine, C. (2000). Virtual ethnography. London: Sage.

Hine, C. (2004). Social research methods and the Internet: A thematic view. Sociological Research Online, 9(2). Retrieved March 3, 2014, from http://www.socresonline.org.uk/9/2/hine.html

Hine, C. (2005). Researcher relationships and online relationships: Introduction. In C. Hine (Ed.), Virtual methods: Issues in social research on the internet (pp. 17-20). London: Berg.

Illingworth, N. (2001). The internet matters: Exploring the use of the internet as a research tool. Sociological Research Online, 6(2). Retrieved December 15, 2013, from http://www.socresonline.org.uk/6/2/illingworth.html

James, N., \& Busher, H. (2009). Online interviewing. London: Sage.

Jones, M., \& Alony, I. (2011). Guiding the use of grounded theory in doctoral studies - An example from the Australian film industry. International Journal of Doctoral Studies, 6, 95-114. Retrieved from http://ijds.org/Volume6/IJDSv6p095-114Jones322.pdf

Jones, S. (1999). Studying the net: Intricacies and issues. In Jones S. (Ed.), Doing internet research: Critical issues and methods for examining the net (pp.1-28). Thousand Oaks: Sage.

Jowett, A., Peel, E., \& Shaw, R. (2011). Online interviewing in psychology: Reflections on the process. Qualitative Research in Psychology, 8(4), 354-369. 
Kivits, J. (2005). Online interviewing and the research relationship. In C. Hine (Ed.), Virtual methods: Issues in social research on the internet (pp. 35-49). Oxford: Berg.

Kvale, S. (1996). Interviews: An introduction to qualitative research interviewing. Thousand Oaks: Sage.

Mann, C., \& Stewart, F. (2000). Internet communication and qualitative research: A handbook for researching online. London: Sage.

Meho, L. (2006). E-mail interviewing in qualitative research: A methodological discussion. Journal of the American Society for Information Science and Technology, 57(10), 1284-1295.

Murray, C. (2004). An interpretative phenomenological analysis of the embodiment of artificial limbs. Disability and Rehabilitation, 26(16), 963-973.

Nicholas, D., Lach, L., King, G., Scott, M., Boydell, K., Suawatzky, B., Resiman, J., Schippel, E., Young, N. (2010). Contrasting internet and face-to-face focus groups for children with chronic health conditions: Outcomes and participant experiences. International Journal of Qualitative Methods, 9, 105121.

O'Connor, H., \& Madge, C. (2003). Focus groups in cyberspace: Using the Internet for qualitative research. Qualitative Market Research: An International Journal, 6(2), 133-143.

Opdenakker, R. (2006). Advantages and disadvantages of four interview techniques in qualitative research. Forum: Qualitative Social Research, 7(4), Art. 11.

Pennebaker, J. (1993). Putting stress into words: Health, linguistic and therapeutic implications. Behavior Research and Therapy, 31(6), 539-548.

Pew Research Center. Millennials (2010). A portrait of generation next. Retrieved February 3, 2014, from http://pewsocialtrends.org/assets/pdf/millennials-confident-connected-open-to-change.pdf

Ratislavová, K., \& Ratislav, J. (2014). Asynchronous email interview as a qualitative research method in the humanities. Human Affairs, 24(4), 452-460.

Sammel, A. (2003). An invitation to dialogue: Gadamer, hermeneutic phenomenology, and critical environmental education. Canadian Journal of Environmental Education, 8(1), 155-168.

Seymour, W. (2001). In the flesh or online? Exploring qualitative research methodologies. Qualitative Research, 1(2), 147-168.

Synnot, A., Hill, S., Summers, M., \& Taylor, M. (2014). Comparing face-to-face and online qualitative research with people with multiple sclerosis. Qualitative Health Research, 24(3), 431-438.

Tanis, M. (2007). Online social support groups. In A. Joinson, K. McKenna, T. Postmes, \& U. Reips (Eds.). The Oxford handbook of internet psychology (pp. 139-153). Oxford, UK: Oxford University Press.

Tates, K., Zwaanswijk, M., Otten, R., van Dulmen, S., Hoogerhrugge, P., Kamps, W., \& Bensing, J. (2009). Online focus groups as a tool to collect data in hard-to-include populations: Examples from pediatric oncology. BMC Medical Research Methodology, 9(15).

Turkle, S. (2011). Alone together: Why we expect more from technology and less from each other. New York, NY: Basic Books.

Voida, A., Mynatt, E., Erickson, T., \& Kellogg, W. (2004). Interviewing over instant messaging, Proceedings CHI '04 Extended Abstracts on Human Factors in Computing Systems, 1344-1347.

Watson, M., Peacock, S., \& Jones, D. (2006). The analysis of interaction in online focus groups. International Journal of Therapy and Rehabilitation, 13(12), 551-557.

Williams, S. (2009). Understanding anorexia nervosa: An online phenomenological approach. (Unpublished $\mathrm{PhD}$ ). Queen Margaret University, Edinburgh.

Williams, S., Clausen, M., Robertson, A., Peacock, S., \& McPherson, K. (2012). Methodological reflection on the use of asynchronous online focus groups in health research. International Journal of Qualitative Methods, 11(4), 368-383. 


\section{Appendix}

Please think about your current home. How important was each of the following to you when deciding whether or not to move into your current home?

It was important to me that my home:

\section{(Well-Being Factors)}

Be easy to clean

Be a place where I can relax

Be a place where I felt secure

Be a place that contributed to my overall well-being

\section{(Social Factors)}

$\mathrm{Be}$ in a location that would be easy for my friends/relatives to visit

Helped me maintain my social contacts

Be part of a community with a thriving social scene

Be located near cultural amenities

\section{(Spaces)}

Have beautifully landscaped outdoor space

Have plenty of room for recreational activities

Have a flexible floor plan so that I could rearrange furniture

\section{(Envirotech)}

Have the most up-to-date features

Be located near public transportation

Be located within a community where I do not have to rely on a car to get around

Be located near my job/school

Have the infrastructure to support my personal technologies

Be equipped with energy-efficient appliances

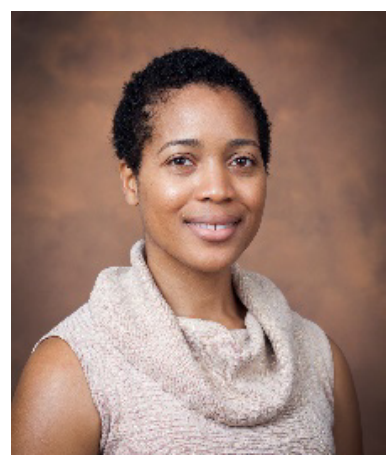

\section{Biographies}

Chandra Bowden is a doctoral student studying how values and lifestyle influence Millennial choice in mixed-use community housing. When she is not working on her dissertation, she supports the University of Florida Division of Enrollment Management in developing statistical models to determine what factors influence freshmen choice to enroll or not enroll in the University.

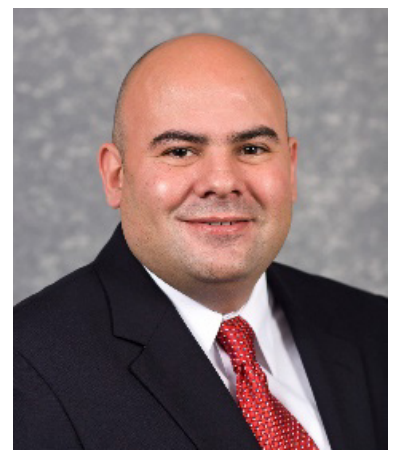

Sebastian Galindo-Gonzalez is a Research Assistant Professor in the Department of Agricultural Education and Communication. He is currently responsible for designing and executing the evaluation components for a variety of multidisciplinary projects in collaboration with a number of scientists inside and outside his university. 